\title{
OS SIGNIFICADOS DO CURSO DE GRADUAÇÃO EM ADMINISTRAÇÃO PARA JOVENS ALUNOS TRABALHADORES
}

\author{
THE IMPORTANCE OF THE BUSINESS ADMINISTRATION \\ DEGREE COURSE FOR YOUNG WORKING STUDENTS
}

\author{
Recebido em: 25/10/2012 Aprovado em: 04/03/2013 \\ Avaliado pelo sistema double blind review \\ Editora Científica: Manolita Correia Lima
}

\section{MARCELO DE REZENDE PINTO marcrez@hotmail.com PAULA KARINA SALUME PONTIFÍCIA UNIVERSIDADE CATÓLICA DE MINAS GERAIS}

\begin{abstract}
RESUMO
Este trabalho tem por objetivo investigar a forma como os alunos de Administração atribuem significados ao curso por meio das diversas atividades cotidianas atinentes à sua interação com a instituição de ensino, bem como nas relações sociais construídas e articuladas por meio dessa interação. Com um enfoque interpretativista, o trabalho de campo foi conduzido por meio da conjugação da grounded theory com a abordagem etnográfica com um grupo de jovens alunos trabalhadores de um curso de Administração de uma universidade privada brasileira. Os resultados apontam que os jovens alunos do curso de Administração ao vivenciarem todas suas experiências com a instituição, com os colegas de sala e de trabalho, com integrantes da família e com outros atores dão sentido a essas experiências em um grande círculo de interação social e convívio. Assim, o consumo de experiências de serviços educacionais pode ser encarado como um importante mecanismo de reprodução social, bem como um fenômeno que pode levar à construção de identidades na atual sociedade. Palavras-chaves: curso de Administração; consumo simbólico; significados do curso.

\section{ABSTRACT}

This study aims to investigate how Business Administration students attribute meanings to their course through the various daily activities relating to their interaction with their HEI (Higher Education Institution), as well as the social relationships built and articulated through such interaction. The interpretivism-focused fieldwork was conducted using a combination of grounded theory and an ethnographic approach, while the sample group comprised young, working students from the Business Administration degree course of a private Brazilian university. The results show that young students give meaning to the experiences built up from their interaction with the HEI, their colleagues and fellow students, family members and other actors within a large circle of social interaction and socializing. Thus, consuming the experiences of educational services can be regarded as an important mechanism of social reproduction, as well as a phenomenon that can lead to the construction of identities in contemporary society.

Keywords: Business Administration course; symbolic consumption; meanings of the course.
\end{abstract}




\section{INTRODUÇÃO}

Discussões envolvendo questões atinentes ao curso de Administração, bem como à percepção dos alunos quanto ao curso, à instituição de ensino, à carreira e à profissão de administrador não são novas no contexto acadêmico no Brasil. Prova disso é que há anos existe no EnANPAD um espaço dedicado às discussões de questões atinentes a esses temas. Assim, pode-se afirmar que muitos são os estudos que vêm ao longo dos últimos anos tentando escrutinar essas questões nos diversos fóruns e canais destinados à temática.

No tocante aos estudos envolvendo a percepção dos cursos de Administração por parte dos alunos, pode-se verificar que boa parte das pesquisas segue uma linha mais direcionada ao entendimento do curso como uma prestação de serviço, ou seja, a qualidade dos serviços prestados pelas instituições de ensino em termos de corpo docente, de infraestrutura envolvendo biblioteca, sala de aula, laboratório e áreas de convivência, além de atendimento da secretaria, de serviços de apoio entre outros (SOUKI; PEREIRA, 2004; NICOLAO; SPARTEL, 2004; CODA; SILVA, 2004; VELUDO-DEOLIVEIRA; IKEDA, 2006; AR AÚJO et al., 20I0). Outros trabalhos caminharam no sentido de buscar pontes com outras disciplinas ou campos do conhecimento (aQuino; tOMASSINI, 2009; LOMbardi; ARAújo; teiXeira, 2009). Também é possível encontrar pesquisas com foco na motivação dos estudantes em cursar Administração (MIRANDA; SILVA, 2003; SILVA; MACHADO, 2006; CAMARGOS et al., 2008; FALCÃO; ROSA, 2008), bem como estudos contemplando a concepção deles do curso à luz de uma abordagem crítica (BATISTA-DOssantos et al., 20II). Levando-se em consideração, porém o contexto de um considerável estrato em termos numéricos de alunos composto na sua maioria por jovens trabalhadores com pouca disponibilidade de tempo para se dedicar aos estudos, sem formação pregressa adequada, com família e filhos para dividir seu tempo, sem o apoio da família, é que parece emergir algumas indagações: como os jovens estudantes trabalhadores do curso de graduação em Administração constroem os significados relacionados ao consumo de experiências de atividades de ensino? Quais são os aspectos mais relevantes do consumo de experiências nas diversas interações entre 
a instituição de ensino e os estudantes? De que forma as diversas situações do cotidiano vivenciadas pelos estudantes do curso de Administração contribuem para a construção de significados na experiência de consumo nas atividades de ensino?

Com base nessas indagações ainda pouco exploradas por outros estudos no Brasil, é que surgiu o interesse em empreender uma pesquisa empírica na qual se investigasse a forma como os jovens estudantes trabalhadores do curso de graduação em Administração de uma grande universidade privada brasileira atribuem significados ao curso de Administração e vivenciam suas experiências de consumo nas diversas atividades cotidianas atinentes à sua interação com a instituição de ensino, bem como nas relações sociais construídas e articuladas por meio dessa interação. Como as teorias gerais existentes não conseguem explicar todos seus aspectos relevantes relacionados a esse público e também a questões relativas ao consumo de experiências de ensino, julgou-se adequado lançar mão da metodologia da grounded theory conjugada com a abordagem etnográfica.

A ideia foi desenvolver um estudo de cunho etnográfico em que seja relatado o cotidiano dos jovens alunos trabalhadores do curso de Administração com especial ênfase na sua vida vivida costurada e articulada nas relações sociais construídas na família, na escola, no trabalho, etc. Em outras palavras, como as experiências com o curso podem ser entendidas em uma perspectiva, tanto experiencial, quanto social e simbólica. Nesse sentido, vale enfatizar que a proposta da presente pesquisa representa um passo adiante, ou seja, busca entender a construção de significados articulados no cotidiano dos alunos com vistas a compreender melhor de que forma são criados, mantidos e (re)negociados os valores, as práticas, os mecanismos de fruição e os processos de mediação social presentes nas vidas desses indivíduos. Por isso, o caráter pioneiro e inovador da proposta.

Para isso, estruturou-se o trabalho da seguinte forma: inicialmente, foi elaborada uma seção visando a revisar sucintamente alguns pontos importantes sobre o consumo com ênfase na ampliação de suas abordagens, conceitos e perspectivas, bem como apresentar alguns pontos atinentes à noção experiencial e à perspectiva cultural e simbólica do consumo, 
com vistas a identificar lacunas e interlocuções entre esses campos de estudo. A seção posterior destacará o percurso metodológico adotado. Em seguida, são apresentados os principais resultados do trabalho, com foco nas categorias que emergiram ao longo das fases de coleta e análise de dados. Por fim, as duas últimas seções destacam o retorno à literatura e as reflexões finais. 


\section{O CONSUMO: AMPLIANDO CONCEITOS, PERSPECTIVAS E} ABORDAGENS

Embora o consumo seja frequentemente visto como algo mundano, para não dizer fútil, da vida social, um olhar mais cuidadoso sobre ele e suas implicações pode levar a conexões sobre um mais apurado entendimento de alguns dos elementos mais centrais da sociedade contemporânea, quais sejam: as crenças acerca do que é a verdade e a realidade (BARBOSA, 2006). Para Laburthe-Tolra e Warnier (I997, p. 4I6-4I7), “[...] o consumo pode ser definido como o uso de bens e serviços que desempenha uma dupla função: produzir a identidade, o sentido e a sociabilidade, ao mesmo tempo em que satisfaz as necessidades dos consumidores”. Também para esses autores o consumo é fonte de identidade pessoal e coletiva, uma vez que os bens são produtores de sentido. Ou seja: “[...] são signos que permitem a comunicação entre os iniciados, a inclusão por identificação ao grupo, a intromissão em um grupo ao qual o sujeito deseja pertencer e a exclusão de indivíduos ou grupos que não compartilham das normas recebidas” (LABURTHE-TOLRA; WARNIER, I997, p. 4I7).

Para além de entendê-lo como um artefato histórico, ao longo dos séculos, o consumo, por conseguinte, tornou-se um campo de investigação complexo, ambíguo e elusivo, visto que passou a englobar várias atividades, atores e um conjunto de bens e serviços que, frequentemente, não se restringem necessariamente aos fornecidos sob a forma de mercadorias (BARBOSA; CAMPBELl, 2006). O que dizer, por exemplo, do consumo de atividades altamente intangíveis e perecíveis como os serviços em suas várias classificações e características? E do consumo de significados tão presentes na comercialização de ideias, lugares e organizações? E o marketing pessoal e político nos quais fica implícito algo tão etéreo como um significado ou uma marca construída socialmente? No mesmo sentido, o que pode ser dito do consumo de experiências como atividades de entretenimento, lazer e turismo? Uma vez que o consumo é uma prática eminentemente positiva, produtora de imaginações e realidades articuladas pelo próprio consumidor e considerando-se que as atividades de ensino também envolvem consumo, 
os alunos também não consomem experiências em seu dia a dia no contato com as instituições de ensino, com seu corpo docente, com funcionários do administrativo, com seus colegas de sala e com profissionais de outras áreas e competências?

Levando-se em consideração o reconhecimento da crescente complexidade das práticas de consumo e os modos pelos quais tais práticas, de maneira igualmente complexas, estão envolvidas nas vidas cotidianas de indivíduos concretos (MILLER, 2002) é que parece residir a ideia central do presente trabalho: o consumo de experiências e, mais precisamente, o consumo de experiências em instituições de ensino.

\section{A ABORDAGEM EXPERIENCIAL DO CONSUMO}

A noção de experiência entrou no campo do consumo com o artigo seminal de Holbrook e Hirschman (1982), em que destacavam a crescente importância, até então negligenciada pelos pesquisadores de consumo, da visão experiencial, marcada por um fluxo de fantasias (sonhos, imaginação, desejos inconscientes), sentimentos (emoções tais como amor, ódio, raiva, inveja, divertimento) e diversão (prazer hedônico derivado de atividades divertidas, alegres e prazerosas) associado ao consumo.

Apesar disso e passadas três décadas da publicação do trabalho de Holbrook e Hirschman (1982), o conceito ainda parece ser elemento-chave no campo do consumo (CARÙ; COVA, 2003), embora seja fácil perceber que algumas lacunas e desafios permaneçam evidentes (BRASIL, 2007). Contudo, com base nas contribuições de diversos autores de diferentes campos do conhecimento, é possível estabelecer que a experiência de consumo é uma ocorrência pessoal, não raramente com significante importância emocional, fundada na interação com estímulos de produtos e serviços consumidos (HOLBROOK; HIRSCHMAN, 1982). No mesmo sentido, na visão desses autores, vale ressaltar que a abordagem experiencial é fenomenológica e considera o consumo como um estado primariamente subjetivo de consciência, com uma variedade de significados simbólicos, respostas hedônicas e critérios estéticos. Pullman e Gross (2003) estabelecem que experiências são inerentemente emocionais e pessoais e abrangem fatores como 
interpretações pessoais de uma situação com base em um histórico cultural, experiências anteriores, humor e traços de personalidade.

Nesse sentido, as experiências de consumo não focam apenas aspectos funcionais e objetivos dos produtos e serviços, mas, sim, todos os eventos, atividades e detalhes capazes de proporcionar valor em todas as fases do consumo, por exemplo, o design do ambiente, a interação com outras pessoas, a construção de sentimentos e significados, e, até mesmo, aspectos emocionais (BRUNER, I986).

Diante de todas essas discussões, algumas questões parecem emergir: Seria possível estabelecer uma interlocução entre o campo da experiência de consumo e o entendimento do consumo como algo eminentemente cultural, construído socialmente nas relações entre os indivíduos?; e Como se dão essas conexões nas situações cotidianas de consumo em instituições de ensino? Com base nessas inquietações é que se julgou importante elaborar a próxima seção do trabalho, cujo objetivo é discutir, ainda que sucintamente, as questões atinentes ao consumo, em uma perspectiva social e simbólica.

\section{A ABORDAGEM SOCIAL E SIMBÓLICA DO CONSUMO}

Esta seção tem o objetivo de apresentar o consumo em uma perspectiva cultural e simbólica com base nos entendimentos de vários autores que investigam como o consumo se conecta com outras esferas da experiência humana e de que forma ele funciona como uma conexão para o entendimento de múltiplos processos sociais e culturais (MCCRACKEN, 2003; ARNOULD; THOMPSON, 2005; DOUGLAS; ISHERWOOD, 2006).

Dessa forma, cabe enfatizar que o consumo pode ser entendido como eminentemente cultural. Isso porque, em primeiro lugar, todo consumo envolve significado. Um indivíduo, para ter uma necessidade e agir em função dela, precisa ser capaz de interpretar sensações, experiências e situações, ao mesmo tempo em que necessita dar sentido a vários objetos, ações e recursos em relação a essas necessidades. Em segundo lugar, o consumo é sempre cultural, porque os significados envolvidos são partilhados, isto é, as preferências individuais são formadas no interior das culturas. Em terceiro lugar, todas as formas de consumo são culturalmente específicas. 
Isso quer dizer que elas são articuladas conforme ou em relação a formas de vida significativas e específicas. Por fim, é por meio de formas de consumo culturalmente específicas que (re)produzimos culturas, relações sociais e a sociedade. Em outras palavras, conhecendo e usando os códigos de consumo de sua cultura, um indivíduo reproduz e demonstra sua participação em uma determinada ordem social (SLATER, 2002).

Rocha e Barros (2004) também colocam pontos importantes que parecem pertinentes para pensar o consumo em uma perspectiva cultural e simbólica: o consumo é um sistema de significação; o consumo é como um código e, por meio, dele são traduzidas boa parte das nossas relações sociais; esse código, ao traduzir sentimentos e relações sociais, forma um sistema de classificação de coisas e pessoas, produtos e serviços, indivíduos e grupos.

\section{ARTICULANDO A ABORDAGEM EXPERIENCIAL E SIMBÓLICA DO CONSUMO}

A proposta teórica do trabalho caminha no sentido de tentar conciliar ou buscar interlocuções entre a literatura atinente às experiências de consumo na perspectiva das teorias da cultura do consumo, ou seja, construir um conhecimento ou estabelecer relações teóricas que busquem integrar a noção experiencial do consumo com o sistema cultural e simbólico dos sujeitos envolvidos no fluxo da vida social cotidiana. Ao trazer a proposta teórica para o caso da pesquisa, pode-se afirmar que se pretendeu investigar como são construídos os significados do consumo de experiências por parte dos jovens estudantes do curso de graduação em Administração com base na mediação das relações e práticas culturais, bem como das relações desses indivíduos com a cultura material em sua vida social cotidiana, tanto na escola quanto no seu dia a dia no trabalho e com a família, amigos e outros grupos sociais.

\section{O CURSO DE ADMINISTRAÇÃO: RESGATANDO ALGUMAS QUESTÕES IMPORTANTES}

Pode-se afirmar que a trajetória do ensino de Administração no Brasil guarda grande semelhança com que aconteceu nos demais países do terceiro 
mundo. Nicolini (2004) divide essa trajetória em cinco grandes momentos. O primeiro deles aconteceu no início do século XX, quando foram criados, no Rio de Janeiro e em São Paulo, os primeiros estudos de Administração. O segundo momento se dá com a influência do modelo americano no ensino de Administração quando, na década de i940, representantes da Fundação Getúlio Vargas visitaram diversos cursos de Administração Pública sediados em universidades americanas. Essa fase é caracterizada pela influência estrangeira no ensino de Administração e pela imitação de difusão, mas apresenta uma tendência à normatização. Já o terceiro momento tem como principal característica a regulamentação da profissão e do ensino de Administração. O fato marcante acontece em i966, quando há a regulamentação do ensino de Administração por meio de resolução na qual se fixa o conteúdo mínimo e a duração do curso. No quarto momento, percebe-se uma tentativa de se atualizar o ensino no curso tendo em vista as mudanças ocorridas no ambiente dos negócios principalmente nos anos 1980. Por fim, o quinto momento inicia-se com a promulgação da nova LDB e aponta a promulgação das novas diretrizes curriculares como o novo marco regulatório do ensino de Administração que derruba o modelo anterior baseado no currículo mínimo (NICOLINI, 2004).

Um fato a se considerar no tocante ao curso de Administração é a sua considerável expansão evidenciada pela proliferação de escolas e principalmente por meio de faculdades isoladas e privadas a partir dos últimos anos do século xx (FISCHER, 2000). As estatísticas mostram que, no último decênio, os cursos de graduação em Administração multiplicaramse expressivamente. Atualmente são Ir.80o cursos (contando apenas Administração geral) em todo País (INEP/MEC, 20II). Segundo dados do Censo da Educação Superior de 2009, os cursos de Administração são os que concentram o maior número de alunos, totalizando I.I02.579, sendo 874.076 matriculados no ensino presencial e 228.503 matriculados no ensino a distância, o que corresponde a I8,5\% do total das matrículas. 


\section{PERCURSO METODOLÓGICO DA PESQUISA EMPÍRICA}

Em face do objetivo proposto para o trabalho e da natureza dos fenômenos que serão investigados, os quais parecem contemplar alto nível de contradição e fluidez, adotou-se uma estratégia qualitativa de pesquisa, uma vez que a proposta caminha no sentido de levar em consideração uma abordagem naturalista, interpretativa para o mundo, na qual os pesquisadores tentam estudar as coisas em seu ambiente natural, procurando entender ou interpretar os fenômenos em termos dos significados que as pessoas a eles conferem.

O desenho da pesquisa se desenvolveu tendo por base uma abordagem etnográfica conjugada com os pressupostos da grounded theory. A aderência da etnografia ao objetivo do trabalho está relacionada com a proposta de observar, participar e entrevistar o nativo em suas condições reais de existência, tentando entender e mapear a completude de sua vida, os diferentes princípios, as lógicas e os significados por meio dos quais as pessoas atribuem sentido e organizam a realidade em que vivem (GEERTZ, I989; rocha; barros; Pereira, 2005). Por sua vez, a grounded theory se caracteriza como uma metodologia ou movimento de pesquisa útil em casos nos quais o objetivo da investigação é entender como as pessoas se comportam em um contexto social (sTRAUSs; CORBIN, 2008). Essencialmente, ela é mais comumente utilizada para gerar teoria em que pouco é sabido ou existem lacunas no conhecimento (GOULDING, 2002). Ademais, pode ser entendida como um método indutivo de pesquisa em que o pesquisador, ao invés de forçar pressuposições ou categorias/conceitos teóricos préexistentes, ou seja, de tomar a teoria como ponto de partida; deveria procurar conceber uma teoria fundamentada em dados representativos da realidade dos sujeitos estudados.

O desenvolvimento da pesquisa pode ser dividido em cinco grandes fases: revisão da literatura e definição da questão da pesquisa, delimitação e concepção do campo de estudo, trabalho de campo, análise e interpretação dos dados e retorno à literatura.

Na fase de revisão da literatura e definição da questão da pesquisa, vale 
destacar um aspecto fundamental. Em estudos baseados na grounded theory, o pesquisador não começa seu projeto com uma teoria preconcebida. Ao contrário, opta por iniciar com uma área de estudo, permitindo que a teoria surja dos dados. Assim, não se assume um referencial teórico a priori. Pelo contrário, o pesquisador deve se limitar a apresentar um breve estado da arte da área de conhecimento, com vistas a perceber lacunas na literatura (BANDEIRA-DE-MELLO; CUNHA, 2006).

Quanto à etapa da delimitação da pesquisa, optou-se por conduzir uma investigação com jovens estudantes do curso de graduação em Administração de uma das unidades localizadas em Belo Horizonte de uma grande universidade particular de Minas Gerais. O recorte para a escolha dos entrevistados é que todos deveriam ser jovens (menos de 30 anos), terem alguma experiência profissional anterior ao curso e estarem trabalhando no momento da pesquisa.

O trabalho de campo, que conjugou características etnográficas com o aporte operacional da grounded theory, pode ser dividido em duas fases. A primeira, conduzida entre fevereiro e abril de 2orI, consistiu de conversas informais com diversos estudantes do curso, a fim de identificar alguns traços básicos do cotidiano deles no tocante à percepção relativa ao curso, à atividade de administrador, bem como questões relacionadas ao seu ambiente de trabalho e familiar. Nesse período, tornou-se interessante a adoção de uma ferramenta essencial quando se trata de um trabalho etnográfico - o diário de campo (MARIAMPOLSKI, 2006). Os pesquisadores envolvidos, após as conversas com os alunos, digitavam suas impressões. Esse procedimento mostrou-se útil na etapa da análise dos dados, quando o retorno a essas notas permitia relembrar algumas questões levantadas. A segunda fase, que aconteceu entre os meses de maio a novembro de 20II, foi marcada pela realização de entrevistas semiestruturadas. Julgou-se adequado finalizar as entrevistas quando se atingiu o que Strauss e Corbin (2008) chamam de saturação teórica, que pode ser descrita como "o ponto no desenvolvimento da teoria em que não surgem novas propriedades, dimensões ou relações durante a análise”.

No tocante à escolha dos entrevistados, no caso deste trabalho, a mais adequada foi a denominada amostragem teórica (STRAUSs; CORBIN, 
2008; CHARMAZ, 2006; GOULDING, 2002), pois, quando se constroi teoria indutivamente, a amostragem é direcionada pela própria teoria (GOULDING, 2002). Assim, pode-se definir amostragem teórica como coleta de dados conduzida por conceitos derivados da teoria evolutiva e baseada no conceito de fazer comparações, cujo objetivo é procurar locais, pessoas ou fatos que maximizem oportunidades de descobrir variações entre conceitos e de tornar densas as categorias em termos de suas propriedades e de suas dimensões (sTrauss; CORBIN, 2008, P. 196). A ideia inicial para fazer parte do corpus da pesquisa era que os alunos deveriam ter, no máximo, 30 anos. Durante a primeira fase, porém achou-se conveniente incluir alguns poucos alunos com idade um pouco superior a fim de estender o poder explicativo da teoria que estava sendo criada. Assim, I5 estudantes fizeram parte do corpus da pesquisa. A idade deles variava de 22 a 38 anos.

Quanto à análise dos dados coletados, pode-se dizer que essa fase consiste em uma das principais etapas do método da grounded theory, visto que as categorias emergem dos dados. Ademais, é a análise que conduz à coleta de dados. Outra importante etapa da análise dos dados foi a codificação dos dados, que é também de extrema importância para o método da grounded theory (GOULDING, 2002; CHARMAZ, 2006). Para tais pesquisadoras, o processo pode ser dividido em três etapas: codificação aberta, codificação axial e codificação seletiva. A codificação aberta envolveu a quebra, análise, comparação, conceituação e categorização dos dados. Foram gerados ${ }^{4} 42$ códigos que puderam ser agrupados em sete categorias. Após a identificação de categorias conceituais pela codificação aberta, a codificação axial examinou as relações entre categorias e subcategorias. Por fim, a codificação seletiva refinou todo o processo, identificando a categoria central da teoria, com a qual todas as outras estão relacionadas. Como técnica de análise de dados, optou-se pela utilização da análise qualitativa de conteúdo (BARDIN, 20II), uma vez que o objetivo era identificar o que estava sendo dito a respeito das experiências dos estudantes. Vale comentar que na, grounded theory, há uma sobreposição entre as fases de coleta e análise de dados. Assim, toda a fase de análise de dados começou com base na elaboração das 
primeiras notas de campo e somente terminou com a redação do trabalho final. Em todo o processo de análise de dados foi utilizado o software de tratamento de dados qualitativos ATLAs/ti, versão 4.I.

Por fim, conduziu-se o retorno à literatura. Pode-se dizer que é uma etapa importante, visto que é o momento em que o pesquisador se (re)encontra com a literatura existente sobre o tema investigado, a fim de comparar as proposições identificadas pela teoria substantiva. 


\section{APRESENTAÇÃO E DISCUSSÃO DOS RESULTADOS}

Nesta seção serão apresentadas discussões referentes à categoria central do estudo e, em seguida, as principais discussões que emergiram na fase de análise de dados: articulação entre vida profissional, pessoal e acadêmica; características do curso; dia a dia na sala de aula; instituição de ensino; questões familiares; relacionamentos; simbolismos e inclusão. Vale destacar que os nomes apresentados nas citações são fictícios.

\section{A CATEGORIA CENTRAL}

Com base nas análises conduzidas ao longo das fases de codificação aberta, axial e seletiva, pode-se finalmente, tentar responder a questão que acompanha o pesquisador em uma investigação baseada no método da grounded theory: sobre qual fenômeno tratam os dados? No caso deste trabalho, o fenômeno está relacionado às formas como os jovens estudantes trabalhadores do curso de Administração vivenciam suas experiências de consumo em instituições de ensino. Frente a essa análise, pareceu adequado considerar que as experiências dos alunos são permeadas de questões simbólicas, fruto de uma construção social articulada no dia a dia e costurada tanto na escola, como no seu dia a dia no trabalho e com a família, quanto amigos e outros grupos sociais.

\section{ARTICULAÇÃO ENTRE VIDA PROFISSIONAL, PESSOAL E ACADÊMICA}

Em todas as entrevistas é muito forte a sensação de que os alunos têm um dia a dia atribulado e bastante corrido, pois levantam cedo e, depois de um dia inteiro de trabalho, precisam estar dispostos a participar das aulas. Essa situação é ainda mais complicada para as mães que precisam compatibilizar essa rotina com afazeres domésticos e cuidados com os filhos. Aqueles alunos que têm filhos, por exemplo, passam boa parte da semana sem vê-los.

"Cansativo... Acordo às 6 horas e já ajeito o café, enquanto isso ela toma banho. Pego ela [a filha] e levo para escola, deixo na escola. 7 horas já estou na firma. Faço curso de inglês de 7 às 8 horas. 8 horas pego serviço e vou até às 17 , I8 horas. Venho para a faculdade e da faculdade vou para casa." (Cássia) 
"Normalmente eu acordo o5h45min, e vou trabalhar... pego serviço o7h3omin, largo às I7hı8min, e neste intervalo,geralmente passo rapidinho em casa, tomo um banho... tenho meia hora pra ir pra casa, tomar um banho e ir pra aula...aí venho pra aula... depois da aula eu chego em casa muito cansada...” (Noemy)

"Olha... a dificuldade maior é a questão do tempo, sabe? Hoje em dia, assim... tudo muito corrido... tudo é pra ontem, né? Então, assim... é... a maior dificuldade que eu encontro é essa!” (Elmo)

$\mathrm{Na}$ análise das entrevistas ficou bastante explícita a dificuldade, principalmente para as mulheres, em conciliar afazeres domésticos e faculdade, marido, filhos etc. Ainda que muitos digam que os maridos e esposas apoiem a decisão do cônjuge em freqüentar o curso, algumas das narrativas deixam transparecer que existem cobranças, conflitos, atritos e outros problemas entre os casais quanto à dedicação do parceiro no curso.

"Ela [a filha] fica até onze horas esperando. E fica mesmo. Até dez e meia ela está lá acordada. Eles reclamam que não tem comida em casa...” (Cássia)

"Talvez não dê muita força porque meu marido não faz curso superior..." (Diana)

"Algumas coisas fica até difícil pra ele entender: eu chegar da faculdade II horas da noite e, se no outro dia tiver que trabalhar e tiver que entregar um trabalho, eu ter que ir para o computador fazer esse trabalho à noite, porque é o único momento que eu tenho pra ficar com meu marido, sabe?” (Jaqueline) Uma estratégia bastante citada pelos alunos para permitir que eles possam conciliar com maior tranquilidade as atividades do curso (em questões de tempo e custo) é a diminuição do número de disciplinas a cursar. Isso leva a alguns problemas como problemas de criar raízes no curso, tendo em vista a dificuldade em seguir uma turma, perda de identidade, isolamento com relação às turmas, além de problemas relacionados à montagem do horário principalmente no final do curso.

Em suma, falta para os alunos, portanto, maior tempo para se dedicar às atividades do curso. Percebe-se, assim, que a sala de aula funciona como um local único para aprendizado, pois os alunos não terão outra oportunidade de tempo para estudar. Essa questão será discutida na próxima seção. 


\section{DIA A DIA NA SALA DE AULA}

Nas diversas fases da pesquisa, ficou bastante explícita a constatação de que os alunos não dispõem de tempo para se dedicar de forma adequada às atividades extracurriculares como participação em projetos de extensão, pesquisa, monitoria e acompanhamento de outras atividades como palestras, minicursos, bem como cursos de idiomas e outros eventos de curta duração que poderiam enriquecer o currículo deles. Os alunos não têm tempo para se dedicar aos estudos em casa com leituras de livros, pesquisas na internet e mesmo trabalhos em grupo. Isso limita muito a capacidade dos alunos em ter um curso de qualidade. Conciliar mais de oito horas de trabalho, afazeres domésticos e aulas à noite exige uma grande dose de habilidade.

No discurso dos alunos, fica bastante clara a necessidade que eles têm de investir no aprendizado em sala de aula, pois não terão condições de se dedicar aos estudos fora do horário em que estão na faculdade. Isso parece levar a uma constatação importante: para os jovens alunos trabalhadores do curso de Administração, a graduação se resume no aprendizado em sala de aula, sem o aporte de outras experiências extraclasse que poderiam aprimorar a formação deles: pesquisa, extensão e outras atividades extracurriculares.

Outra questão que também emergiu, tanto nas conversas informais quanto nas entrevistas, foi o pouco tempo disponibilizado pelos alunos para o estudo. É comum alguns alunos se gabarem de que estudaram muito para uma determinada prova. Segundo alguns deles, ficaram de meia noite às duas e acordaram cedo para estudar. Outros falam que passaram a tarde de domingo estudando, dando a ideia de que esse tempo é demasiadamente extenso. Ou seja, os alunos não têm o hábito de estudar. Também não se sentem envergonhados com isso, pois não se incomodam quando questionados sobre essa prática.

Notou-se alguma dicotomia com relação às disciplinas do curso. Os alunos gostam de dividi-las em de cálculo e teóricas. Vários deles gostam de dizer: sou bom em matérias de de cálculo e ruim em matérias teóricas. Outros falam justamente o contrário. É difícil encontrar alunos que dizem gostar de ambas. Aqueles que têm maior facilidade com as disciplinas da área 
quantitativa, muitas vezes, apresentam algum orgulho ao fazer esta afirmação.

A utilização de e-mails, redes sociais e torpedos é recorrente entre os alunos, pois é a oportunidade que têm de se comunicarem ao longo do dia acerca de questões relacionadas aos trabalhos em sala, matérias de provas etc. Vale citar também casos do que alguns estudantes chamam de e-colas, ou seja, resumos da matéria que são passados via e-mail para grupos de alunos ou até todos os integrantes da turma que podem ser utilizados para consulta durante as avaliações.

É bastante comum também a divisão dos trabalhos. Isso pode ter repercussão negativa no rendimento acadêmico dos discentes, pois está baseada em uma fragmentação do conhecimento que pode não ser adequada. Assim, muitos acabam se especializando em determinadas tarefas como redigir o trabalho, montar a apresentação ou apresentar o trabalho. Ainda que isso possa ter seu valor, pode, do ponto de vista de formação do aluno, apresentar pontos negativos. Ademais, a vivência e as conversas informais e as entrevistas conduzidas permitem afirmar que, em suma, o dia a dia na sala de aula dos alunos é permeado por emoções e sentimentos diversos, tanto negativos como raiva, frustração, cansaço, apatia, quanto positivos como alegria, prazer, diversão entre outros.

\section{CARACTERÍSTICAS DO CURSO}

Ficou bastante óbvia a constatação de considerar o curso de Administração fácil de acompanhar. Isso gera algum preconceito com relação a outros amigos e colegas de trabalho que veem os cursos da área de exatas como as engenharias ou da área de saúde, por exemplo, como cursos mais difíceis. Essa constatação não parece incomodar os entrevistados, pois eles não veem o curso dessa forma. Pode-se chegar a falar de que, para alguns, o curso é chamado de Distração. Alguns alunos chegam a declarar que não têm o hábito de estudar e, mesmo assim, conseguem excelentes notas em disciplinas consideradas difíceis.

Uma questão porém é clara: muitos alunos chegam ao curso meio que por acaso. Como o vestibular não é empecilho, muitos alunos, após muitos 
anos sem estudar, conseguem a aprovação e, assim, começam a frequentar o curso. Isso ficou bastante claro em várias entrevistas. Ou seja, o curso não é aquele em que o aluno sonha e luta para conseguir entrar. Alguns alunos chegaram a relatar que ficaram meio perdidos no início do curso, mas depois conseguiram se encontrar devido à generalidade das disciplinas.

"Só que passei de cara na primeira, estudando em casa, sozinho, aí falei: Poxa... Fiquei empolgado, aí entrei no curso de Administração." (Abílio)

"Eu sempre tive na cabeça que queria fazer Engenharia... Engenharia Elétrica, mas de repente, quando consegui a bolsa, pensei: "vão tentar, vamos ver como é que é”... e no ${ }^{\circ}$ e $2^{\circ}$ período é muita teoria, logo de cara... aí depois eu comecei a gostar do curso, quando entrou nas matérias mais específicas..." (Noemy)

Alguns alunos são enfáticos ao defender a ideia de que Administração é o curso de quem não tem opção, de quem não sabe o que fazer ou começa o curso como segunda opção. Por outro lado, o curso também tem uma matriz curricular ampla, com disciplinas diversas oriundas de diferentes campos do conhecimento, o que pode oferecer alguma possibilidade de colocação no mercado no futuro.

"Na verdade eu queria fazer engenharia civil, como eu não passei em engenharia civil e passei em Administração fui fazer Administração... foi minha $2^{a}$ opção... que eu queria sentir o que era faculdade e depois até trocar de curso." (Maria)

Outra questão que merece destaque está relacionada à percepção de que não houve planejamento financeiro e operacional por parte dos alunos na ocasião em que tomaram a decisão em cursar a graduação em Administração. Isso pode ser explicado pelo que foi explicitado anteriormente: a facilidade para ingressar no curso. Em um momento em que sobram vagas nas instituições de ensino, os alunos não precisam passar por complexos e árduos processos seletivos para ingressarem na graduação. Vários alunos disseram ter passado no vestibular no susto. Posteriormente, eles tiveram que se adequar tanto no tocante ao acompanhamento das disciplinas quanto em questões financeiras.

Vale destacar também que muitos entrevistados dissertam que o curso 
parece ser chamativo para os alunos indecisos em virtude da facilidade que os discentes têm para conseguirem estágio mesmo nos períodos iniciais do curso. Alguns alunos, por exemplo, conseguem bons estágios em grandes empresas nos primeiro ou segundo períodos do curso. Talvez esse seja um chamativo interessante.

Notou-se uma expressiva frustração por parte dos alunos principalmente aqueles no final do curso no que tange ao papel do administrador na sociedade. Isso ficou muito claro em alguns discursos, quando eles afirmam que qualquer um pode administrar. Assim, o curso perde o seu valor, pois parece que todos os anos de estudo não serviram para aumentar as condições de empregabilidade, pois aqueles profissionais sem formação, muitas vezes apenas com ensino médio, podem administrar. $\mathrm{O}$ mesmo pode ser dito com relação à invasão da área por outros profissionais como engenheiros, economistas, psicólogos etc.

\section{INSTITUIÇÃO DE ENSINO}

Esta categoria está relacionada à forma como os alunos percebem a instituição de ensino na qual estão matriculados e principalmente como se dá a articulação da imagem dessa instituição com a formação. É evidente que a questão da marca da instituição tem seu valor para o aluno, principalmente quando se constata que o curso de Administração é um dos cursos mais vendáveis por parte das instituições de ensino por serem de baixo custo e terem uma procura considerável pelos alunos. Conforme apresentado e discutido no tópico anterior, em face da crença atribuída ao curso de Administração como uma graduação fácil, para quem ainda está indeciso quanto à escolha do curso, os alunos tendem a se sentir mais aliviados e justificar a não aceitação desse preconceito ao verbalizar que existem dois tipos de cursos de Administração: os de faculdades pequenas e, portanto, de qualidade discutível, e aqueles oferecidos por instituições conhecidas como as públicas federais e outras mais tradicionais. Em outras palavras, o discurso caminha no sentido de afirmar:Faço administração, mas faço em uma faculdade melhor do que as outras.

Outra questão tangente a essa categoria que foi levantada na pesquisa 
está relacionada à ideia de que alguns alunos de classe média baixa preferem estudar em uma escola particular que tem horário bem estabelecido, normalmente noturno, para terem a oportunidade de fazerem estágio e/ ou trabalharem. Isso não seria possível ao entrar em uma instituição pública federal, por exemplo, na qual os horários impedem esse tipo de atividade.

\section{QUESTÕES FAMILIARES}

Ficou bastante evidente nas fases da pesquisa que não houve influência por parte dos familiares no sentido de cursar uma faculdade e, muito menos, o curso de Administração. Algumas explicações podem ser apontadas para explicar tal fato. Em primeiro lugar, boa parte dos alunos entrevistados, por serem de baixa renda e terem bolsa, é oriunda de famílias nas quais os pais e mães não têm curso superior. Muitos não têm sequer o ensino médio. Muitos dos entrevistados enfatizam que são um dos poucos da família que irão se graduar. Isso é um dado interessante que remete à questão do simbolismo presente em algumas das interações existentes ao longo do curso, principalmente naquelas de final de curso como a missa de formatura, colação de grau, baile entre outras. Essa questão será devidamente discutida em outra seção. A exceção fica por conta daqueles alunos que, ao dizerem que não tiveram outra alternativa a não ser entrar na graduação pois toda a família é graduada, reafirma a influência da formação dos pais na decisão do filho em cursar uma faculdade.

Percebe-se em algumas entrevistas um sentimento de orgulho ao estar cursando uma faculdade, pelo fato de essa experiência não fazer parte do universo deles no seio da família da qual fazem parte. Fica bastante claro nos discursos que eles não viam essa possibilidade há anos atrás, isto é, seria algo inatingível para eles em outros momentos das vidas deles. Entra em cena, nesses casos, a importância das bolsas institucionais e principalmente das financiadas pelos programas do governo como o Universidade Para Todos (PRO-UNI), as quais possibilitam o ingresso de alunos nos cursos de graduação que, de outra forma, não seria possível. Isso parece levar a algumas consequências, até certo ponto, negativas. Em alguns momentos, fica bastante perceptível também que eles não se sentem à vontade para 
reclamar de algo que não parece bom, pois cursar uma faculdade é muito maior do que era possível. Isto é, eles não se sentem propensos a reclamar. Ganha destaque o papel do coordenador de curso que funciona como um ouvidor, gerente, resolvedor de problemas, psicólogo, conselheiro e outras atribuições com a função de solucionar todas as pendências dos alunos.

Em segundo lugar, pode ser apontada também que esses alunos começaram a trabalhar com pouca idade, em atividades operacionais e de baixa qualificação como atendentes, auxiliar de escritório e até motoristas de ônibus. Funções estas que não necessitam de uma formação mais abrangente.

\section{RELACIONAMENTOS}

Parece que há um bom relacionamento entre os colegas de sala. Não foram citados conflitos, problemas e aborrecimentos entre os alunos da mesma turma. Aqueles alunos que vieram de transferência de outras instituições e de outros cursos, por exemplo, citam que foram bem acolhidos pelos colegas. Alguns deles revelaram que havia pensado em desistir do curso por dificuldades financeiras, mas que estava chegando ao final por causa da ajuda e apoio que receberam dos colegas durante todo o curso.

"Você acha vários sentidos: pessoal, amizade, a convivência com as pessoas é muito boa, a experiência que você tem na sala, você vê que não é aquele mundo só seu ali...” (Cássia)

“Boa... Boa. Tem uma relação boa... a gente acabou fazendo muitas amizades, né? Já é um ano juntos... conhecendo muitas pessoas... é um relacionamento muito bom." (Diana)

Uma questão que foge ao escopo do trabalho, mas que emergiu nas várias fases da pesquisa tem a ver com os relacionamentos com os professores. $\mathrm{Na}$ concepção deles, é essencial que o professor, que consiga se aproximar da turma, tratá-los com o devido respeito, saber dialogar, ainda que não tenha todas as competências técnicas para lecionar a disciplina. Para eles, são estes os professores marcantes, que não se restringem a explicar o conteúdo da disciplina, mas sabem educá-los para vida e para o mercado de trabalho.

$\mathrm{Na}$ visão dos entrevistados, o fato de eles estarem cursando um curso 
de graduação em Administração não mudou o relacionamento com os colegas de trabalho de menor instrução, muitos menos com as amizades conquistadas em outras fases da vida. No que tange ao relacionamento com os chefes e com profissionais com cargos maiores no ambiente de trabalho, alguns alunos chegaram a afirmar que eles, após o ingresso no curso, passaram a receber maior reconhecimento e apreço.

Contudo, a grande constatação da pesquisa no que diz respeito a essa categoria está relacionada com a ideia da faculdade como um lócus privilegiado para o desenvolvimento de uma série de atividades eminentemente relacionais como paquerar, namorar, brincar, ir para bares, baladas, aumentar o networking, churrascos nos finais de semana, convites para jogar bolas entre outras. É interessante observar que a rede de relacionamentos vai desde utilização de e-mails, redes sociais e torpedos, até festas na casa de um dos colegas de turma.

\section{SIMBOLISMOS}

Uma questão que emergiu nas fases da pesquisa está relacionada com os aspectos simbólicos presentes em várias ocasiões ao longo da experiência de consumo do aluno com a instituição e com o curso. A primeira dessas ocasiões tem a ver com a aprovação no vestibular. Apesar de ser um processo seletivo bastante simplificado, sem muita concorrência quando comparado à seleção de cursos ou instituições com grande procura por parte dos estudantes, os alunos ainda dão algum valor simbólico a esse rito de passagem. Muitos se sentiram felizes quando perceberam que os familiares ficaram orgulhosos ao ver alguém fazendo curso superior. O trecho seguinte retrata isso.

"Mas eu sinto que eles têm muito orgulho de mim. Quando eu contei pra eles que tinha passado no vestibular, eles ficaram radiantes." (Maria)

Outra ocasião seria o momento da colação de grau, da missa, dos cultos e das festas envolvendo a formatura. Ficou bastante perceptível a importância que as famílias, consideradas de menor nível educacional dão a esses momentos. Vale a pena ressaltar a importância que os alunos atribuem a esse momento para os familiares, incluindo pais, avós, tios etc. Parece ser um momento 
importante na trajetória deles.

"Na colação de grau, acho que seria interessante... Todos os familiares estando lá, né? E você recebendo o diploma... Aquela apresentação toda pra sociedade... Acho que vai ser bastante interessante, realmente... Seria... mostrar pra toda a sociedade toda aquela batalha que eu tive nos quatro anos pra realizar, chegar naquele momento... conseguir o diploma.” (Abílio)

"Os pais têm orgulho. Por mais que eles não tenham incentivado. Digamos que eu fui praticamente com as minhas costas; eu corri atrás, eu batalhei." (Irineu)

Ademais, os alunos parecem dar grande importância simbólica ao diploma. Boa parte deles atrela o diploma ao sentimento de orgulho, realização de um sonho, aumento da empregabilidade, satisfação da família, elevação da autoestima, capacidade para enfrentar desafios, perseverança entre outros. O fato de ter obtido uma vaga em um curso de graduação em uma universidade reconhecida também é motivo de orgulho por parte dos alunos. Conforme já discutido anteriormente, alguns alunos chegam a afirmar que "existem cursos e cursos de Administração". Assim, ter no diploma a marca de uma instituição de peso ou de "grife" é algo que também tem uma carga simbólica considerável para os alunos.

\section{INCLUSÃO}

Pôde-se perceber uma latente expectativa por parte dos alunos no que tange ao crescimento profissional e, principalmente, o incremento na renda pessoal depois da obtenção do título de graduação. Vale ressaltar que algumas das alunas entrevistadas ressaltaram a independência como um benefício que esperam com o ensino superior. Os alunos também apontaram o fato de que o curso de Administração oferece uma boa oportunidade de inserção no mercado de trabalho já nos primeiros semestres do curso com a oferta de diversas vagas de estágios em boas empresas que oferecem benefícios interessantes. Dessa forma, pode-se considerar que o ingresso em um curso de graduação em Administração permite ao aluno a inserção na sociedade de consumo atual. 
Baseada na explanação, ainda que resumida, das principais categorias que emergiram na pesquisa, torna-se adequado confrontar os resultados da pesquisa com a literatura existente, o que será conduzido na seção seguinte.

\section{RETORNO À LITERATURA}

O retorno à literatura constitui a última fase do processo de pesquisa, envolvendo o método da grounded theory. Pode-se dizer que é uma etapa importante, visto que é o momento em que o pesquisador se (re)encontra com a literatura existente sobre o tema investigado, a fim de verificar coincidências e dissidências nos resultados encontrados (CHARMAZ, 2006).

assim sendo, levando-se em consideração a noção experiencial do consumo, pode-se estabelecer algumas conexões com os resultados da pesquisa. Conforme os autores, a experiência de consumo pode ser entendida, não apenas por aspectos funcionais e objetivos dos produtos, mas, sim, por todos os eventos, atividades e detalhes capazes de proporcionar valor em todas as fases do consumo, por exemplo, a interação com outras pessoas, a construção de sentimentos e significados e, até mesmo, aspectos emocionais. Na pesquisa ficou bastante explicitado que os jovens alunos trabalhadores vivenciam nas experiências de consumo relacionadas com a instituições de ensino diversos momentos como sonhos, desejos, sentimentos como amor, ódio, raiva, divertimentos e atividades alegres, tristes, divertidas e prazerosas tal como propostas pelos autores Holbrook e Hirschman (1982). Do mesmo modo que apontado por Miller (2002), o consumo pode ser entendido como uma prática cotidiana, que faz parte do dia a dia de todo e qualquer indivíduo, até porque também faz parte do todo social no qual os indivíduos se inserem. O consumo de experiência de ensino não está livre da constatação do autor.

No tocante à perspectiva social e simbólica do consumo, pode-se afirmar que os resultados do trabalho confirmam que é interessante e adequado compreender o consumo de produtos, serviços e, até mesmo, ideias como uma espécie de facilitador, propiciador e construtor de relações sociais. Assim, a noção das experiências de consumo com instituições de ensino no plano simbólico implica atrelar aos significados dessas experiências 
as dinâmicas de sociabilidade às quais se entrelaçam. Em outras palavras, os resultados parecem ter alguma aderência com a perspectiva social e simbólica do consumo, uma vez que a instituição de ensino pode ser pensada como um espaço de encontros que possibilita formas de relacionamentos e trocas sociais concretas em um círculo de interação social e convívio, marcadas por diversas questões como convivência, interação, socialização, associação, pertencimento e manifestações de visões de mundo, estilos de vida, desejos e sonhos (PORTILHO, 2009). No mesmo sentido, os lugares são territórios carregados de significados compartilhados por uma coletividade, e é possível supor que, em uma coletividade que frequenta determinadas instituições de ensino, haja diferentes tipos de pessoas partilhando um conjunto de experiências e signos, ainda que, em outras situações, tais pessoas não compartilhem mais nada (CORREA, 2009).

Outro ponto que parece ter coincidência com a literatura é o que se foca na questão dos relacionamentos. Isso tem aderência ao que é explicitado por DaMatta (1997) quando afirma que a sociedade brasileira é relacional, na qual o valor fundamental é relacionar, juntar, confundir, conciliar. Dessa forma, nesse sistema socialmente construído, os indivíduos são obrigados a visitar pessoas, comer bebidas, dar presentes, assinar manifestos, frequentar locais e, até mesmo, casar, não porque individualmente se quer, mas porque há uma demanda relacional. Ou seja, é a relação que exige, e não o indivíduo que deseja. Essa constatação de DaMatta (1997) também pode ser visível na construção de redes que possibilita a troca de provas de semestres anteriores, exercícios prontos, informações sobre os professores entre outros.

O fato de os alunos considerarem o curso de Administração fácil de passar e acompanhar e um curso sem status faz com que eles busquem uma forma de compensação na instituição de ensino escolhida por eles que tem a característica de tradicional e de qualidade. Essa constatação encontra eco na compreensão da natureza cultural do consumo tal como analisada por Bourdieu (2007). Assim, mais importante do que cursar Administração em uma determinada instituição, o interessante é investigar o uso de que os indivíduos são capazes de fazer com essa informação. O termochave para esse processo social é o que ele chama de distinção, termo que 
parece englobar o sentido de sistemas classificatórios por meio dos quais os indivíduos distinguem as coisas, bem como o uso dessas coisas e de seus significados para conseguir distinção nas relações sociais.

Uma outra questão que ficou clara na condução do trabalho tem a ver com o valor do diploma atribuído pelos estudantes pesquisados. Cruz e Martins (2006), ao discutirem o papel do bacharelismo na cultura brasileira, trazem à baila o conceito de capital social que, tal como proposto por Bourdieu (2007), funciona como legitimação de poder que parece estar relacionado ao bacharelismo, haja vista que, em nossa sociedade, quem detém capital social alcança maior poder. Dessa forma, o bacharelismo no País pode ser entendido como um tipo de poder condicionado, cuja principal característica é a inferiorização do indivíduo que não tem um título. Esse resultado corrobora a discussão empreendida por Sarsur, Cruz e Barbosa (1998), visto que eles concluíram que os títulos acadêmicos são um dos requisitos básicos para inserção no mercado de trabalho. 


\section{CONSIDERAÇÕES FINAIS}

Em face dos resultados apresentados, torna-se útil retornar às indagações que motivaram a elaboração do trabalho. Ao fazer isso, pode-se afirmar que os jovens alunos do curso de Administração, ao vivenciarem todas as suas experiências com a instituição, com os colegas de sala e de trabalho, com integrantes da família e com outros atores dão sentido a essas experiências em um grande círculo de interação social e convívio. O consumo de experiências de serviços educacionais pode ser encarado como um importante mecanismo de reprodução social, bem como um fenômeno que pode levar a diferentes possibilidades de ação política, assim como na construção de identidades na atual sociedade. Dessa forma, podese dizer que as experiências de consumo com as instituições são repletas de simbolismos construídas no dia a dia por meio das diversas interações sociais existentes. Ou seja, para se entender o valor do diploma é necessário acessar a construção dos significados de ter um título na sociedade brasileira, construção essa que tem raízes na nossa formação histórica, política e social. No mesmo sentido, os relacionamentos, além do papel ainda tradicional da esposa e mãe que precisa dar conta de todos os afazeres domésticos, além de trabalhar e estudar também podem ser analisados à luz de questões ligadas à cultura brasileira.

Cabe destacar também que os resultados do estudo podem constituir um caminho revelador para os gestores da instituição que tenham a pretensão de compreender melhor seus estudantes e, consequentemente, implementar estratégias de comunicação e relacionamento mais adequadas e eficazes.

No tocante à escolha metodológica adotada para o trabalho, não é escusado afirmar que a articulação entre a abordagem etnográfica e a grounded theory mostrou-se adequada e aderente ao problema de pesquisa, uma vez que elas permitiram lidar com as ambiguidades, fluidez e contradições da vida real, ao mesmo tempo em que exploraram os significados construídos e as experiências vividas pelas pessoas. Ou seja, o estudo aponta possibilidades para se chegar àquilo que os entrevistados realmente fazem, pois privilegiou uma visão de perto e de dentro com o pesquisador, procurando entender 
a lógica que orienta a vida desses indivíduos em seu próprio contexto construído histórica e culturamente. Vale destacar que a proposta do trabalho não era generalizar os resultados, até mesmo porque essa não é (ou não deveria ser) o objetivo de uma pesquisa baseada na grounded theory. Assim, o alcance do trabalho é justamente entender a construção de significados de um público específico, bem delimitado e restrito geográfica e culturalmente. Isso não impede que novos estudos sejam conduzidos com o mesmo objetivo e, a partir daí, confrontar os resultados e verificar em que pontos os estudos apresentaram tópicos coincidentes ou discordantes.

Torna-se adequado porém, discutir algumas limitações da pesquisa. $\mathrm{O}$ trabalho focou suas análises em um estrato de discentes: jovens alunos trabalhadores. Isso pode se constituir em uma limitação, pois, certamente, são alunos mais experientes, maduros e que veem o curso de uma forma diferente de outros estratos como, por exemplo, alunos recém-saídos do ensino médio. No mesmo sentido, a pesquisa se limitou a apenas alunos de uma das unidades da universidade. Isso pode ser considerado uma limitação pelas características marcantes dos discentes dessa unidade: são alunos carentes, oriundos de famílias com baixa formação etc. Certamente, se a pesquisa fosse feita com alunos de outros campi da Universidade ou em outras instituições, a percepção poderia ser diferente. Ademais, vale considerar que as entrevistas foram conduzidas por um professor do curso. Isso certamente pode ter enviesado as respostas, pois os alunos podem não ter se sentido à vontade para falar mais abertamente sobre os problemas, dificuldades relacionadas com o convívio com os professores, funcionários e outros.

Sendo assim, também é possível apontar algumas sugestões para estudos complementares, que possam contribuir para uma base de conhecimento sobre os temas aqui tratados. Uma delas tem a ver com aumentar o recorte dos alunos entrevistados, bem como investigar as mesmas questões em cursos diurnos e oferecidas em instituições públicas de ensino. Seria interessante também avaliar a percepção de alunos que ainda não têm experiência profissional. Ademais, pesquisar outros contextos de ensino de administração como, por exemplo, o ensino de administração pública 
e confrontar os resultados da percepção de profissionais que atuam diretamente no ensino de graduação em administração como professores, coordenadores de curso, e diretores acadêmicos entre outros.

Por fim, nunca é demais frisar que o objetivo do trabalho não foi fechar as indagações que motivaram o estudo, muito menos oferecer um conjunto de respostas conclusivas para as novas perguntas que surgiram ao longo do trabalho, que não foram poucas. Muito pelo contrário. A expectativa dos autores é trazer à baila as discussões, construir novas perguntas, questionar verdades absolutas no sentido de convidar outros pesquisadores do campo a refletirem sobre as questões aqui expostas e, principalmente, debater a temática que, certamente, compreende uma grande complexidade. 


\section{REFERENNCIAS}

AQUINO, R. D.; TOMASSINI, R. O consumo para os estudantes de administração: uma aplicação da teoria do núcleo central de representações sociais. In: EnANPAD, 33., 2009, São Paulo. Anais... São Paulo: ANPAD, 2009.

ARAUJO, S. P. M.; BOAVENTURA, J.M.G.; TELLES, R.; SIQUEIRA, J.P.L.; ROBIC, A.R. Fatores de escolha da carreira de administração e da instituição de ensino. Administração: Ensino e Pesquisa, v. 11, n. 2, p. 163-90, 2010.

ARNOULD, E.; THOMPSON, C. J. Consumer Culture Theory (CCT): twenty years of research. Journal of Consumer Research, v.31, n.4, p. 868-82, 2005.

BARBOSA, L. Apresentação. In: BARBOSA, L.; CAMPBELL, C. (Orgs.). Cultura, consumo e identidade. Rio de Janeiro: FGV, 2006, p. 7-18.

BARBOSA, L.; CAMPBELL, C. O estudo do consumo nas ciências sociais contemporâneas. In: BARBOSA, L. ; CAMPBELL, C. (Orgs.). Cultura, consumo e identidade. Rio de Janeiro: FGV, 2006, p. 21-44.

BARDIN, L. Análise de conteúdo. São Paulo: Edições 70, 2011.

BANDEIRA-DE-MELLO, R.; CUNHA, C. J. C. de A. Grounded theory. In: GODOI, C. K; BANDEIRA-DE-MELLO, R.; SILVA, A. B. (Orgs.). Pesquisa qualitativa em estudos organizacionais: paradigmas, estratégias e métodos. São Paulo: Saraiva, 2006, p. 241-66.

BATISTA-DOS-SANTOS, A. C.; PELOGIO, E.A.; CARDOSO, M.F.; LEITE, Y.V.P.; ALEXANDRE, M.L.O. Uma escuta ao alunado de administração: suas concepções de administração e administrador à luz de uma abordagem crítica. Administração: Ensino e Pesquisa, v. 12, n. 2, p. 163-90, 2011.

BOURDIEU, P. A distinção: crítica social do julgamento. São Paulo: Edusp, 2007.

BRASIL, V. S. Experiência de consumo: aspectos conceituais, abordagens metodológicas e agenda de pesquisa. In: EnANPAD, 31., 2007, Rio de Janeiro. Anais... Rio de Janeiro: ANPAD, 2007.

BRUNER, E. W. Experience and its expressions. In: TURNER, V. W.; BRUNER, E. M. (eds.). The anthropology of experience. Urbana: University of Illinois Press, 1986, p. 3-30.

CAMARGOS, M. A.; GODINHO, L. A. C.; CAMARGOS, M. C. S.; SANTOS, F. S.; RODRIGUES, P. J. Motivos da escolha, percepções e perspectivas de alunos de IES privadas de Minas Gerais. E-civitas, v. 1, n.1, p. 1-21, 2008.

CARÙ, A.; COVA, B. Revisiting consumption experience: a more humble but complete view of the concept. Marketing Theory, v. 3, n. 2, p. 267-86, 2003.

CHARMAZ, K. Constructing grounded theory: a practical guide through qualitative analysis. London: Sage Publications, 2006. 
CODA, R.; SILVA, D. Sua escola de administração é uma excelente escola para se estudar? Descobrindo dimensões da satisfação de alunos em cursos de Administração: uma contribuição metodológica. In: EnANPAD, 28., 2004, Curitiba. Anais... Curitiba: ANPAD, 2004.

CORREA, S. B. Lazer, trabalho e sociabilidade na Praia de Copacabana. In: BARBOSA, L.; PORTILHO, F.; VELOSO, L. (Orgs.) Consumo: cosmologias e sociabilidades. Rio de Janeiro: Mauad X, 2009, p. 135-56.

CRUZ, B. P. A.; MARTINS, P. E. M. O poder do bacharel no espaço organizacional brasileiro: relendo raízes do Brasil e sobrados e mucambos. Cadernos Ebape.BR. v. 4, n. 3, p. 1-9, 2006.

DaMATTA, R. A casa e a rua: espaço, cidadania, mulher e morte no Brasil. 5.ed. Rio de Janeiro: Rocco, 1997.

DOUGLAS, M.; ISHERWOOD, B. O mundo dos bens: para uma antropologia do consumo. Rio de Janeiro: Editora UFRJ, 2006.

FALCÃO, D. F.; ROSA, V. V. Um estudo sobre a motivação dos universitários do curso de Administração: Uma contribuição para gestão acadêmica no âmbito público e privado. In: EnANPAD, 32., 2008, Rio de Janeiro. Anais... Rio de Janeiro: ANPAD, 2008.

FISCHER, T. M. D. A Difusão do Conhecimento sobre Organizações e Gestão no Brasil: seis propostas de ensino para o decênio 2000/2010. In: EnANPAD, 24., 2000, Curitiba, Anais... Curitiba: ANPAD, 2000.

GEERTZ, C. A interpretação das culturas. Rio de Janeiro: LTC editora, 1989.

GOULDING, C. Grounded theory: a practical guide for management, business and market researchers. London: Sage publications, 2002.

HOLBROOK, M. B.; HIRSCHMAN, E. C. The experiential aspects of consumption: consumer fantasies, feelings, and fun. Journal of Consumer Research, v. 9, n.1, p. 132-40, 1982.

INEP. Instituto Nacional de Estudos e Pesquisas. Disponível em: $<$ http://portal.inep.gov. $\mathrm{br} /$ web/censo-da-educacao-superior $>$. Acesso em 21/07/2011.

LABURTHE-TOLRA, P.; WARNIER, J. Etnologia-antropologia. Petrópolis: editora Vozes, 1997.

LOMBARDI, M. F. S.; ARAÚJO, B. F. B.; TEIXEIRA, M. L. M. Os estudantes de graduação em administração de empresas e seus valores básicos: um estudo em duas universidades da cidade de São Paulo. In: EnEPQ, 2, 2009, Curitiba. Anais... Curitiba: ANPAD, 2009.

MARIAMPOLSKI, H. Ethnography for marketers: a guide to consumer immersion. London: Sage publications, 2006.

MCCRACKEN, G. Cultura e consumo: novas abordagens ao caráter simbólico dos bens e das atividades de consumo. Rio de Janeiro: Mauad, 2003. 
MILLER, D. Teoria das compras: o que orienta as escolhas dos consumidores. São Paulo: Nobel, 2002.

MIRANDA, N. A.; SILVA, D. Expectativas profissionais dos alunos do ensino superior noturno de administração de empresas. Revista Lumem, v. 9, n. 20, p. 55-74, 2003.

NICOLAO, L.; SPARTEL, L. B. Julgamentos pós-escolha do curso de administração: o papel da qualidade percebida, da satisfação e do arrependimento e os seus comportamentos subseqüentes. In: EnANPAD, 28., 2004, Curitiba. Anais... Curitiba: ANPAD, 2004.

NICOLINI, A. A Trajetória do ensino de administração analisada por um binóculo institucional. In: EnANPAD, 28., 2004, Curitiba. Anais... Curitiba: ANPAD, 2004.

PORTILHO, F. Sociabilidade, confiança e consumo na feira de produtos orgânicos. In: BARBOSA, L.; PORTILHO, F.; VELOSO, L. Consumo: cosmologias e sociabilidades. Rio de Janeiro: Mauad X, 2009, p. 61-86.

PULLMAN, M.; GROSS, M. Welcome to your experience: where you can chack out anytime you'd like, but you can never leave. Journal of Business and Management, v. 9, n. 3, p. 215-32, 2003.

ROCHA, E.; BARROS, C. F. P. Dimensões culturais do marketing: teoria antropológica, estudos etnográficos e comportamento do consumidor. In: EnANPAD, 28., 2004, Curitiba. Anais... Curitiba: ANPAD, 2004.

ROCHA, E.; BARROS, C.; PEREIRA, C. Fronteiras e limites: espaços contemporâneos da pesquisa etnográfica. In: CAVEDON, N. R.; LENGLER, F. B. (Orgs.) Pós-modernidade e etnografia nas organizações. Santa Cruz do Sul: EDUNISC, 2005, p.121-43 .

SARSUR, A. M.; CRUZ, M. V.; BARBOSA, A. C. Q. Carreira: utopia ou realidade? In: Enangrad, 9., 1998, Itu-SP. Anais... São Paulo: ANGRAD, 1998.

SILVA, W. R.; MACHADO, M. A. V. Motivos que levam os alunos a cursar graduação em administração: um estudo nas instituições públicas e privadas do estado da Paraíba. In: EnANPAD, 30., 2006, Salvador. Anais... Salvador: ANPAD, 2006.

SLATER, D. Cultura do consumo e modernidade. São Paulo: Nobel, 2002.

SOUKI, G. Q. ; PEREIRA, C. A. Satisfação, motivação e comprometimento de estudantes de administração: um estudo com base nos atributos de uma instituição de ensino superior. In: EnANPAD, 28., 2004, Curitiba. Anais... Curitiba: ANPAD, 2004.

STRAUSS, A.; CORBIN, J. Pesquisa qualitativa: técnicas e procedimentos para o desenvolvimento da teoria fundamentada. 2.ed. Porto Alegre: Artmed, 2008.

VELUDO-DE-OLIVEIRA, T. M.; IKEDA, A. A. Valor em serviços educacionais. RAEEletrônica, v. 5, n. 2, p. 1-20, 2006. 


\section{DADOS DOS AUTORES}

\section{MARCELO DE REZENDE PINTO^ marcrez@hotmail.com Doutor em Administração pela UFMG}

Instituição de vinculação: Pontifícia Universidade Católica de Minas Gerais Belo Horizonte/MG - Brasil

Áreas de interesse em pesquisa: Consumo, Pesquisa do Consumidor e Consumer Culture Theory.

*Av. Itaú, 525 Dom Cabral Belo Horizonte/MG 30535-050

PAULA KARINA SALUME paulasalume@hotmail.com Mestre em Administração pela PUC Minas

Instituição de vinculação: Pontifícia Universidade Católica de Minas Gerais Belo Horizonte/MG - Brasil

Áreas de interesse em pesquisa: Consumo e Arranjos Produtivos. 